\title{
Insulinoma resembling a rapid eye movement sleep behavior disorder: a case report
}

This article was published in the following Dove Medical Press journal: International Medical Case Reports Journal

Kenji Kishi

Kazutoshi Kubo

Tetsu Tomita

Kazuhiko Nakamura

Norio Yasui-Furukori

Department of Neuropsychiatry, Hirosaki University Graduate School of Medicine, Hirosaki, Japan
Correspondence: Norio Yasui-Furukori Department of Neuropsychiatry, Hirosaki University Graduate School of Medicine, Zaifu-cho 5, Hirosaki 036-8562, Japan

Tel +8 I I 72395066

Fax +8I I72395067

Email yasufuru@hirosaki-u.ac.jp

\begin{abstract}
Some patients with insulinoma present with neuropsychiatric symptoms and are often misdiagnosed with psychiatric disease. We present the case of a 72-year-old Japanese female who exhibited violent behavior while asleep and received a diagnosis of suspected rapid eye movement sleep behavior disorder (RBD). She was admitted to the psychiatry ward after receiving levomepromazine $25 \mathrm{mg}$ intramuscularly. The patient's blood glucose level was 27 $\mathrm{mg} / \mathrm{dL}$ at the time of hospitalization, and a biochemical examination revealed that her insulin level was $9.1 \mu \mathrm{U} / \mathrm{mL}$ and C-peptide level was $2.16 \mathrm{ng} / \mathrm{mL}$. A contrast-enhanced computed tomography revealed a mass $8 \mathrm{~mm}$ in diameter in the pancreatic head. The diagnosis was changed from RBD to insulinoma. The sleep behavior disorder disappeared after continuous glucose administration. After enucleation of the insulinoma, the administration of glucose was discontinued, and her blood glucose levels recovered. This case suggests that insulinoma should be considered by physicians and psychiatrists in the differential diagnosis of patients with symptoms presenting as RBD.
\end{abstract}

Keywords: insulinoma, differential diagnosis, hypoglycemia, rapid eye movement sleep behavior disorder

\section{Background}

Rapid eye movement (REM) sleep behavior disorder (RBD) is diagnosed when patients present with a clinical history of complex motor dream enactment behaviors during REM sleep and exhibit REM sleep atonia loss on polysomnography (PSG). ${ }^{1-3}$ People who suffer from RBD move their limbs or even rise and engage in activities associated with waking. Some patients engage in sleep talking, shouting, screaming or violent movements such as hitting or punching. ${ }^{1-3}$ The prevalence of RBD has been estimated to be in the range of $0.5 \%-2 \%,{ }^{1-3}$ yet, larger population-based studies of patients with probable dream enactment symptoms suggest that RBD is more common, with an incidence rate between 5\% and 13\% among community-dwelling individuals aged 60-99 years. $^{4-7}$ There is strong evidence suggesting that RBD is linked to the development of neurodegenerative diseases, including Parkinson's disease, Lewy body disease and multiple system atrophy. ${ }^{8}$

Some patients with insulinoma present with neuropsychiatric symptoms and are often misdiagnosed as having psychiatric disease. ${ }^{9,10}$ Patients with hypoglycemia, like those with insulinoma, typically present with neurologic symptoms such as confusion $(80 \%)$, visual disturbances (59\%), amnesia or coma (47\%), abnormal behavior $(36 \%)$ and seizures $(17 \%) .{ }^{11}$ Here, we report a case of a patient with RBD who was later 
diagnosed with insulinoma. The patient provided written informed consent after receiving a full description of the study and consented to the publication of the report.

\section{Case presentation}

We present a case involving a 72-year-old Japanese female who suffered from hypertension and somatization disorder. She developed daytime sleepiness 1 year prior to hospitalization and had been unsteady on her legs, experiencing twilight state three or four at night and exhibiting violent behavior; she also had daytime amnesia. She was diagnosed with dissociative disorder due to workplace stress and was treated with escitalopram $10 \mathrm{mg} /$ day for 2 months. The symptoms appeared to improve, but after the dose was decreased to 5 $\mathrm{mg} /$ day because of nausea, the symptoms recurred. She was examined at our hospital. Her diagnosis was suspected to be RBD or epilepsy rather than dissociative disorder. An electroencephalogram performed on the day she was examined was within normal limits. Brain MRI showed no abnormalities. We prescribed clonazepam $1 \mathrm{mg} /$ day at bedtime. The next morning at 6 am, she was admitted to the emergency room (ER) of our hospital because of her violent behavior. Her injurious disruptive behavior continued in the ER. She was admitted to the psychiatry ward after receiving an intramuscular injection of $25 \mathrm{mg}$ of levomepromazine. Because her blood glucose level was $27 \mathrm{mg} / \mathrm{dL}$ (normal range 73-109 mg/ $\mathrm{dL}$ ) in the morning, the patient underwent further biochemical examinations which revealed that her insulin level was $9.1 \mu \mathrm{U} / \mathrm{mL}$ (normal range $0.0-18.7 \mu \mathrm{U} / \mathrm{mL}$ ), C-peptide level was $2.16 \mathrm{ng} / \mathrm{mL}$ (normal range $0.80-2.50 \mathrm{ng} / \mathrm{mL}$ ) and her insulin/C-peptide ratio was 4.21. An intravenous one-shot injection of $40 \mathrm{~mL}$ of $50 \%$ glucose was administered, and her blood glucose level increased to $175 \mathrm{mg} / \mathrm{dL}, 10$ minutes after the injection. The patient's blood glucose level decreased to $36 \mathrm{mg} / \mathrm{dL}$ in the afternoon. Her blood glucose level was 38 $\mathrm{mg} / \mathrm{dL}$ the next morning; therefore, after a consultation with endocrinologists, $5 \%$ glucose at a rate of $1,500 \mathrm{~mL} / 24$ hours was administered continuously while she was in the hospital. The sleep behavior disorder disappeared after continuous glucose administration. A contrast-enhanced computed tomography revealed a high-density mass, $8 \mathrm{~mm}$ in diameter, in the pancreatic head (Figure 1). Her diagnosis was changed from REM sleep behavior disorder to insulinoma. She was moved from the psychiatry ward to the medical ward of the Department of Endocrinology. We performed a 48-hour fasting blood glucose test, although she was not symptomatic. Her 48-hour fasting blood glucose level was $57 \mathrm{mg} / \mathrm{dL}$, serum insulin level was $5.3 \mu \mathrm{U} / \mathrm{mL}$, C-peptide level was $7.5 \mathrm{ng} /$

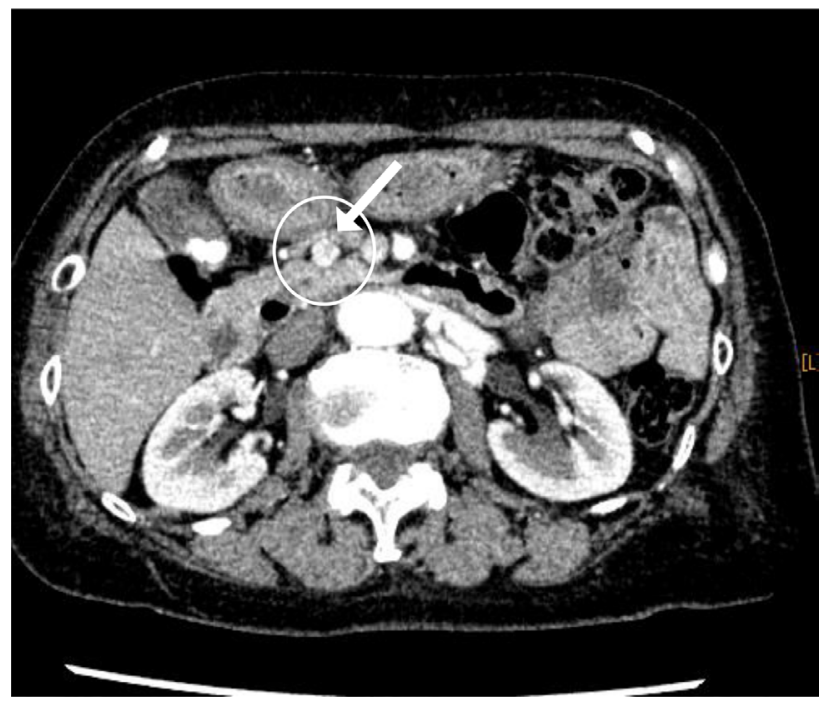

Figure I Enhanced CT scan of the upper abdomen.

Note: The circle and arrow indicate an area of high density, which was diagnosed as an insulinoma on histopathologic examination.

Abbreviation: CT, computed tomography.

$\mathrm{mL}$ and her insulin/C-peptide ratio was 3.73. Her glycemic response was $57,83,110$ and $123 \mathrm{mg} / \mathrm{dL}$ at the baseline and 10,20 and 30 minutes after intravenous injection of glucagon $1.0 \mathrm{mg}$. Eight weeks after these tests, she was admitted to the Department of Gastroenterological Surgery and she underwent enucleation of the insulinoma. After enucleation of the insulinoma, the administration of glucose was discontinued, and her blood glucose level recovered. She was discharged 3 days after the surgery.

\section{Discussion and conclusion}

This case suggests that it is difficult to distinguish between hypoglycemia and RBD. According to the International Classification of Sleep Disorders-2, RBD is defined as the following: 1) the presence of REM sleep without atonia, which is the sustained or intermittent elevation of submental electromyography (EMG) tone or excessive phasic muscle activity in the limb EMG; 2) at least one of the following: sleep-related injurious or potentially injurious disruptive behaviors documented in the patient's history or abnormal REM sleep behaviors documented on PSG; 3 ) the absence of epileptiform activity during REM sleep unless RBD can be clearly distinguished from any concurrent REM sleep-related seizure disorder and 4) the absence of a better explanation for the sleep disorder as any other medical, neurologic disorder or mental disorder; medication use; or substance use disorder. Because PSG was not examined, only one of these four criteria was met. After the administration of continuous glucose, her sleep behavior disorder disappeared. In addition, after 
enucleation of the insulinoma, even when the administration of glucose was discontinued, her symptoms did not reappear. Based on the clinical course, we concluded that her injurious disruptive behavior during sleep was the result of hypoglycemia due to insulinoma and not associated with an RBD.

The major cause of hypoglycemia is the use of oral diabetes agents or insulin, especially in elderly individuals. ${ }^{12}$ For patients without diabetes, hypoglycemia is the result of hyperinsulinemia. Insulinoma is a neuroendocrine tumor derived from insulin-secreting pancreatic beta cells. The clinical manifestations result from endogenous hyperinsulinismrelated hypoglycemia that is identified when plasma glucose concentrations are $<55 \mathrm{mg} / \mathrm{dL}$ in nondiabetic individuals. ${ }^{13}$ Insulinoma is a rare endocrine tumor with an annual incidence of $1-4$ in 1,000,000 individuals and can occur at any age. $^{14-16}$

Suzuki et $\mathrm{al}^{10}$ reported three cases of insulinoma masquerading as RBD, which were similar to our case. Interestingly, these three patients had previously received anticonvulsant drugs for suspected epilepsy, but the medications were ineffective. PSG showed no evidence of REM sleep without atonia in any of the three patients. We did not use PSG because hypoglycemia was identified and the administration of glucose was efficacious, so we were able to rapidly reassess her diagnosis. In addition, hypoglycemia can mimic epileptic seizures and can manifest as seizures. ${ }^{17}$ Patients with hypoglycemia can present with dizziness, ${ }^{18}$ altered behavior, ${ }^{19}$ irrelevant speech and delusions. ${ }^{20}$ Insulinoma presents with various neuroglycopenic manifestations that are reversed by the administration of glucose. Recurrent attacks of hypoglycemia can cause some residual neurologic deficits. ${ }^{21-24}$ Clinicians, therefore, should be aware that although insulinomas are rare, they can mimic parasomnias, such as RBD.

\section{Consent for publication}

Written informed consent was obtained from the patient for publication of this case report. The ethics committee of the School of Medicine at Hirosaki University judged that there was no need to review this case.

\section{Data sharing statement}

All data generated or analyzed during this study are included in this published article.

\section{Author contributions}

All authors contributed to data analysis, drafting or revising the article, gave final approval of the version to be published, and agree to be accountable for all aspects of the work.

\section{Disclosure}

Norio Yasui-Furukori has received grant/research support or honoraria from, and been on the speakers of Dainippon-Sumitomo Pharma, Mochida Pharmaceutical, MSD, and Otsuka Pharmaceutical. All other authors declare no biomedical or financial interests or potential conflicts of interest directly relevant to the content of the present study.

\section{References}

1. Ohayon MM, Schenck CH. Violent behavior during sleep: prevalence, comorbidity and consequences. Sleep Med. 2010;11(9):941-946.

2. Frauscher B, Gschliesser V, Brandauer E, et al. REM sleep behavior disorder in 703 sleep-disorder patients: the importance of eliciting a comprehensive sleep history. Sleep Med. 2010;11(2):167-171.

3. Kang SH, Yoon IY, Lee SD, Han JW, Kim TH, Kim KW. REM sleep behavior disorder in the Korean elderly population: prevalence and clinical characteristics. Sleep. 2013;36(8):1147-1152.

4. Boot BP, Boeve BF, Roberts RO, et al. Probable rapid eye movement sleep behavior disorder increases risk for mild cognitive impairment and Parkinson disease: a population-based study. Ann Neurol. 2012;71(1):49-56.

5. Mahlknecht P, Seppi K, Frauscher B, et al. Probable RBD and association with neurodegenerative disease markers: a population-based study. Mov Disord. 2015;30(10):1417-1421.

6. Adler CH, Hentz JG, Shill HA, et al. Probable RBD is increased in Parkinson's disease but not in essential tremor or restless legs syndrome. Parkinsonism Relat Disord. 2011;17(6):456-458.

7. Tang WK, Hermann DM, Chen YK, et al. Brainstem infarcts predict REM sleep behavior disorder in acute ischemic stroke. BMC Neurol. 2014;14(1):88.

8. Schenck CH, Mahowald MW. REM sleep behavior disorder: clinical, developmental, and neuroscience perspectives 16 years after its formal identification in sleep. Sleep. 2002;25(2):120-138.

9. Nakamura Y, Doi R, Kohno Y, et al. High-dose calcium stimulation test in a case of insulinoma masquerading as hysteria. Endocrine. 2002;19(2):127-130.

10. Suzuki K, Kawasaki A, Miyamoto M, et al. Insulinoma masquerading as rapid eye movement sleep behavior disorder: case series and literature review. Medicine (Baltimore). 2015;94(25):e1065.

11. Taye A, Libutti SK. Diagnosis and management of insulinoma: current best practice and ongoing developments. Res Rep Endocr Disord. 2015;5:125-1333.

12. Budnitz DS, Lovegrove MC, Shehab N, Richards CL. Emergency hospitalizations for adverse drug events in older Americans. $N$ Engl $J$ Med. 2011;365(21):2002-2012.

13. Cryer PE, Axelrod L, Grossman AB, et al. Evaluation and management of adult hypoglycemic disorders: an endocrine society clinical practice guideline. J Clin Endocrinol Metab. 2009;94(3):709-728.

14. Okabayashi T, Shima Y, Sumiyoshi T, et al. Diagnosis and management of insulinoma. World J Gastroenterol. 2013;19(6):829-837.

15. Service FJ. Hypoglycemic disorders. N Engl J Med. 1995;332(17): $1144-1152$.

16. Vaidakis D, Karoubalis J, Pappa T, et al. Pancreatic insulinoma: current issues and trends. Hepatobiliary Pancreat Dis Int. 2010;9: 234-241.

17. Alemdar M, Murat A, Iseri P, Pervin I, Komsuoglu SS, Sener KS. Insulinoma in differential diagnosis of seizure disorder. J Neuropsychiatry Clin Neurosci. 2006;18(2):247-248.

18. Pandey D, Sharma B, Kumar S, Chauhan V, Gupta D, Sharma A. Insulinoma presenting with psychiatric symptoms. J Indian Acad Clin Med. 2004;5:72-74.

19. Halder PJ, Hafeeunnisa P. Pai R, Samsi AB. Case report: insulinoma. J Postgrad Med. 1992;38:202-204. 
20. Renca S, Santos G, Cerejeira J. An insulinoma presenting with hypochondriac delusions and food refusal. Int Psychogeriatr. 2013;25(11):1909-1911.

21. Ebady A, Kucheki A. Case of insulinoma with neuropsychiatric symptoms and infarction. Int J Neurol. 2005;4:2.

22. Dhume VM, Amrapurkar AD, Rege JD, Kandalkar BM, Varthakavi P. Insulinoma: a case report. Indian J Pathol Microbiol. 2004;47:540-541.
23. Striano S, Striano P, Manganelli F, et al. Distal hypoglycemic neuropathy. An insulinoma-associated case, misdiagnosed as temporal lobe epilepsy. Neurophysiol Clin. 2003;33(5):223-227.

24. Gold AE, Marshall SM. Cortical blindness and cerebral infarction associated with severe hypoglycemia. Diabetes Care. 1996;19(9): 1001-1003.

\section{Publish your work in this journal}

The International Medical Case Reports Journal is an international, peer-reviewed open-access journal publishing original case reports from all medical specialties. Previously unpublished medical posters are also accepted relating to any area of clinical or preclinical science. Submissions should not normally exceed 2,000 words or
4 published pages including figures, diagrams and references. The manuscript management system is completely online and includes a very quick and fair peer-review system, which is all easy to use. Visit http://www.dovepress.com/testimonials.php to read real quotes from published authors.

Submit your manuscript here: https://www.dovepress.com/international-medical-case-reports-journal-journal 